\title{
Research in the Medical Laboratory Science Curriculum
}

\author{
RITA M. HEUERTZ
}

\section{LEARNING OBJECTIVES}

1. Identify the value of students experiencing research at the undergraduate level.

2. Describe the recommended procedure for initiating the process of finding and applying for research funds.

3. Recall the real and unreal expectations of the grant submission process.

4. Differentiate among the different funding mechanisms of NIH to identify funding sources specific to MLS.

5. Discuss the process of identifying and defining research projects.

\begin{abstract}
Medical Laboratory Science (MLS) is increasing its numbers of advanced degree offerings and is accelerating involvement in evidence-based practice. Expectations of MLS faculty have increased to include research and scholarship. Many MLS programs have undergraduate requirements for research. To assist MLS faculty as they increase research productivity, information is provided to guide professionals and students striving to expand their research achievements.
\end{abstract}

INDEX TERMS: undergraduate research, inquirybased learning, health educators, clinical laboratory science

Clin Lab Sci 2011;24(4)Suppl;4-54

Rita M. Heuertz, PhD, MT(ASCP), Doisy College of Health Sciences, Saint Louis University, St. Louis, MO

Address for Correspondence: Rita M. Heuertz, PhD, MT(ASCP), Clinical Laboratory Science Department, Doisy College of Health Sciences, Saint Louis University, 3437 Caroline Street, St. Louis, MO 63104-1111, 314977-8610,heuertzr@slu.edu

\section{INTRODUCTION}

Advanced degrees, such as traditional doctorates $(\mathrm{PhD}$, $\mathrm{EdD})$ as well as clinical doctorates (DCLS) and master's level (MS) degrees, are all associated with expectations of research experiences and scholarly activities and publications. The American Society for Clinical Laboratory Science (ASCLS) position paper on the CLS clinical doctorate ${ }^{1}$ states the importance of preparing interdisciplinary health care providers to the proper knowledge level. It has been identified that clinical doctorates or other advanced-degreed professionals will be instrumental in advancing MLS in areas of evidencebased practice and diagnostics development. Importantly, career advancement and tenure for faculty are frequently based upon productive research and scholarship. In addition, undergraduate student involvement in research increases student retention in academics as well as increases the number of students pursuing science, technology, education and mathematics (STEM) disciplines and careers. ${ }^{2}$ Inculcation of enthusiasm is a key element in positive research outcomes. The earlier the undergraduate student is exposed to research, the better it is for the individual. The more engaged the individual student is in academics throughout the earlier years leads to knowledge of how to be an active and life-long learner, which ultimately benefits society. ${ }^{3}$ Of importance is the fact that students enrolled in undergraduate scientific disciplines today are the source of tomorrow's scientists. Identifying and capturing their scientific interest and curiosity are important and makes the thrill of scientific discovery a reality.

\section{INCORPORATING RESEARCH INTO THE CURRICULUM}

Three challenging areas for inclusion of research into MLS degree programs have been identified: (i) how to incorporate research into the curriculum; (ii) how to identify and define research projects; and (iii) how to find funding for research experiences. Currently, there are several means by which research is included in the 


\section{FOCUS: BUILDING RESEARCH THROUGH MLS CURRICULA}

curriculum. One means is by introduction of students to the basics of research (e.g., reading and critiquing journal articles, assessing and writing Institutional Review Board (IRB) or Institutional Animal Care and Use Committee (IACUC) protocols, performing and applying statistics) through a specific course. At some academic sites, this research basics course is followed by a course where the students perform a research project (with MLS, clinical or medical school faculty), write a Senior Paper in journal format (followed by manuscript submission, acceptance and publication when indicated) and present research results in seminar or poster formats. Other sites include the research basics and research experience into the existing curriculum by weaving them into required coursework.

\section{IDENTIFYING AND DEFINING RESEARCH PROJECTS}

Research is an area for which some clinical laboratorians feel untrained and ill-prepared. Many MLS practitioners report lack of adequate resources and insufficient time in the clinical setting to conduct research. ${ }^{4}$ An additional issue of concern is the recruitment and retention of successful MLS faculty in the publish-or-perish, tenure-track environment. ${ }^{5}$ Faculty members need to determine projects that interest them, since they will be initiating and continuing the research, and for which they have a passion, since their enthusiasm is frequently transferred to the students. Importantly, projects need to be defined that have funding potential.

One way to determine what is important for funding purposes is to review grant funding awards and current requests for grant applications at the National Institutes of Health (NIH) website. Another way to identify a project is through case discussions with colleagues where new interpretations are identified or improved diagnostics may be developed as research projects.

A plethora of project types are available to clinical laboratorians. There are educational projects with examples being identification of effectiveness of online teaching aids or comparison of traditional teaching results with those of active learning projects. Many basic science, translational and diagnostics development ideas are realized by MLS professionals and clinical practice offers an abundance of ideas for research projects.

\section{FINDING FUNDS FOR RESEARCH}

Several questions need to be answered relevant to finding funds to support research. What kinds of funding opportunities are available? Where does one find funding sources? How often does one apply for funding? Before answering these questions, however, one needs to be aware of how to start the journey of finding and applying for research funds. First of all, start small. Remember, Rome was not built in a day and neither will your research program mature overnight. A good place to start is to request funding for pilot studies. These tend to be small and less costly projects that are, therefore, more readily fundable. For example, prepare an initial grant application for submission within your institution or to your professional organization. Pilot studies provide preliminary data necessary for larger grants and funded pilot studies initiate a track record or history of funding that enables one to work up to submission of larger grants.

Alignment of the mission of a funding agency with focus of your research is critical for successful grantsmanship. For example, if your research focuses on increased and/or improved healthcare services for the elderly and disabled, then seek out funding sources like the National Institute on Aging (NIA) or the American Association of Retired Persons (AARP). If you are interested in development of more specific panels to identify cardiovascular risk, diagnosis or prognosis, then sources are available like the American Heart Association (AHA) and the American Stroke Association (ASA). Of importance to remember is that finding a funding source specifically focused on your research topic is a better use of your grant-writing time than preparing an application without forethought as to which agency to submit the funding request.

\section{TYPES OF FUNDING OPPORTUNITIES}

Search engines are present that access many different databases to identify matches between research interests and funding opportunities. For example, one can join and search the Community of Science (www.cos.com) that has free registration and identifies funding opportunities that match research interests. A way to search for federal grant opportunities is to access and search the following sites: www.grants.gov, www.nih.gov, and www.nsf.gov. Another database is Sponsored Programs Information Network (SPIN) which is available at www.infoed.org/new_spin/ spinmain.asp.

VOL 24, NO 4 FALL 2011 SUPPLEMENT CLINICAL LABORATORY SCIENCE 4-55 


\section{FOCUS: BUILDING RESEARCH THROUGH MLS CURRICULA}

Many different types of funding opportunities exist. There are grants available through government entities, associations, societies, organizations, corporations, foundations and endowments. Important to remember is that if the idea is good, the proposal solid and focused, the investigator credible for the project and the budget reasonable, then the investigator needs to perform one last task and find the right agency to submit the grant application.

\section{FEDERAL SOURCES}

Probably the largest funding agency is one sponsored by the federal government, the National Institutes of Health (NIH). The NIH is a conglomerate of institutes and centers as well as a Director's Office and the National Library of Medicine (Table 1). NIH is searchable through its website (www.nih.gov). The United States Department of Health and Human Services has a website for learning more about grant funding (http://www.hhs.gov/grants) and a website through which one can search for grant opportunities (www.grants.gov).

Not only does the NIH have many institutes and centers, but it also has many different funding mechanisms. A three digit code is used to identify different funding mechanisms. The first digit of the code is a letter that indicates the type of grant. For example, $\mathrm{T}$ as a first digit indicates the grant type is one designated for training people in the areas of science and research. Other examples are displayed in Table 2. Sample three digit codes and foci of the grant types are displayed in Table 3. NIH has funding mechanisms with research applications directly applicable to MLS professionals, such as F31, K01, K07, K08, R15, R25 and others (Table 3 ).

Another mechanism of funding support sponsored by the federal government is the National Science Foundation (NSF) that supports basic research and education and has discipline-based directorates: Biological Sciences (BIO); Computer and Information Science and Engineering (CISE); Education and Human Resources (EHR); Engineering (ENG); Geosciences (GEO); Mathematical and Physical Sciences (MPS); and Social, Behavioral and Economic Sciences (SBES). NSF is operated and functions very differently from NIH. While NIH frequently funds health-related, mechanism-identifying research, NSF funds curiosity-driven, high impact research. NSF grants frequently provide summer salary support which is of importance in MLS degree programs since many faculty are on 9- or 10-month contracts. Of interest for many MLS faculty and students are funds that are available for undergraduate research through the Education and Human Resources (EHR) directorate. Examples of EHR opportunities are: (i) course, curriculum and laboratory improvement (CCLI); (ii) math and science partnerships (MSP); (iii) historically black colleges and universities (HBCU); (iv) science, technology, engineering and math (STEM); (v) STEM talent expansion program (STEP); (vi) research experiences for undergraduates (REU); and (vii) research in undergraduate institutions (RUI). Other

Table 1. Branches of the National Institutes of Health (NIH)*
TITLE

Office of the Director

National Cancer Institute

National Eye Institute

National Heart, Lung, and Blood Institute

National Human Genome Research Institute

National Institute on Aging

National Institute on Alcohol Abuse and Alcoholism

National Institute of Allergy and Infectious Disease

National Institute of Arthritis and Musculoskeletal and Skin Diseases

National Institute of Biomedical Imaging and

Bioengineering

National Institute of Child Health and Human

Development

National Institute on Deafness and Other

Communication Disorders

National Institute of Dental and Craniofacial Research

National Institute of Diabetes and Digestive and

Kidney Diseases

National Institute on Drug Abuse

National Institute of Environmental Health Sciences

National Institute of General Medical Sciences

National Institute of Mental Health

National Institute of Neurological Disorders and Stroke

National Institute of Nursing Research

National Library of Medicine

Center for Information Technology

Center for Scientific Review

Fogarty International Center for Advanced Study

in the Health Sciences

National Center for Complementary and

Alternative Medicine

National Center on Minority Health and

Health Disparities

National Center for Research Resources

NIH Clinical Center
ABBREVIATION

OD

$\mathrm{NCI}$

NEI

NHLBI

NHGRI

NIA

NIAAA

NIAID

NIAMS

NIBIB

NICHD

NIDCD

NIDCR

NIDDK

NIDA

NIEHS

NIGMS

NIMH

NINDS

NINR

NLM

CIT

CSR

FIC

NCCAM

NCMHD

NCRR

CC
* current as of March 2011 as per the website (www.nih.gov/icd) 


\section{FOCUS: BUILDING RESEARCH THROUGH MLS CURRICULA}

federal sources for research funding are the Department of Energy (DOE), the Department of Defense (DOD), the Army, the Air Force, the National Aeronautics and Space Administration (NASA) and many others.

Table 2. Types of Grants from NIH

\begin{tabular}{ll}
\hline $\mathrm{F}$ & Fellowships \\
$\mathrm{K}$ & Career development grants \\
$\mathrm{L}$ & Loan repayment program \\
$\mathrm{N}$ & Research contracts \\
$\mathrm{P}$ & Program projects and research center grants \\
$\mathrm{R}$ & Research project grants \\
$\mathrm{S}$ & Research-related projects \\
$\mathrm{T}$ & Training grants \\
$\mathrm{U}$ & Cooperative agreements \\
$\mathrm{Y}$ & Interagency agreements \\
\hline
\end{tabular}

* current as of March 2011 as per the website (www.nih.gov)

While the list for funding opportunities may seem limitless, most sources have websites or other means (such as advertisements in professional journals) for announcing requests for proposals or applications (RFP or RFA, respectively). Searching for the right funding opportunity may take a while since you need to find a relevant agency (i.e., one whose mission aligns with your research focus) as well as determine current funding requests and identify proposal deadlines, forms and other submission information for that agency. For assistance in searching and identifying funding avenues, the Office of Research Services at your institution may be able to assist you. This office has databases and time to search for funding opportunities. Importantly, they want you to apply for and obtain grants and are aware of specific requirements, conditions and contingencies of different funding agencies. To help them identify funding sources, it may be useful to provide them with a 1-2 page statement of your research focus and avenues of research interest so they can identify agencies that match your research focus. A final and take-home point here is that, in all likelihood, someone is looking to fund a project just like yours. What you need to do is find that opportunity!

\section{AGENCY, ASSOCIATION, SOCIETY AND ORGANIZATION SOURCES}

Besides federal opportunities for research funding, many agencies, associations, societies and organizations sponsor and fund research. Some ideas are provided in Table 4 but these represent only a small sampling of funding opportunities in this category.

\section{CORPORATE AND FOUNDATION SOURCES}

This source of funding is quite different from previously mentioned ones because each corporation or foundation contracts the researcher for performance of a project in an individually negotiated manner between corporation/foundation and the university/school. There are no hard-and-fast rules to follow and the best thing to do is to contact the Corporation and Foundation Relations (CFR) Office of your institution and ask for assistance. They will find corporations with missions similar to your research interests/goals. Again, it is helpful to provide a 1-2 page document of your research (i.e., Case Statement) that builds your case of why this corporation should be interested in your work. Be sure to send the Case Statement to your institutional office and not to the corporation/foundation directly. Your institutional office will review your Case Statement and contact you for discussion of the project in greater detail after which they will begin the process of solicitation for research sponsorship.

The Case Statement should address several issues, such as: (i) state the research problem or focus; (ii) identify who is involved or affected; (iii) propose a solution to the problem that your work addresses; (iv) identify who will be involved with the project; (v) state how the experiments will be performed and what kind of data will be forthcoming; (vi) state the anticipated cost of the research project; and (vii) define the impact of the project and results on society. If you have a personal story or testimony, include it in the Case Statement to convey strong personal interest and commitment.

The corporate perspective is that research must be strategic, timely and cutting edge. They need specific turn-around-times and work within certain deadlines. From the corporate perspective, a reason to get the Corporate and Foundations Office of your institution involved is to make connections, connections, connections. Corporations usually seek out broad university/ academic partnerships and initial successes between corporation and academic researcher can lead to even more funding.

Foundations are different from corporations in that they are institutions founded and supported by an endowment. Like corporations, they require specific considerations, such as: (i) a contract for working together; (ii) a statement of no publications until certain 


\section{FOCUS: BUILDING RESEARCH THROUGH MLS CURRICULA}

Table 3. Sample 3-Digit Codes and Descriptions for NIH Grants

F31

F32

F33

K01

K02

K05

K07

K08

K12

K30

K99/R00

P01

P30

R01

R03

$\mathrm{R} 13$

R15

R21

R24

R25

R34

S10

T32

T34

T36

T90

U01

U13

Fellowships for pre-doctoral fellows to promote diversity in health-related research leading to $\mathrm{PhD}, \mathrm{MD} / \mathrm{PhD}$, or other combined degree (professional degree and research doctoral degree) in health services, clinical sciences

Fellowships for individual post-doctoral fellows

Fellowships for experienced researchers wishing to make major changes in research direction

Supervised research career development in health services field (support, protected time)

Career development for newly independent scientists (salary support, protected time)

Career development for outstanding senior scientists to allow focus on research and mentoring of new investigators (protected time)

Career development for improving curricula and enhancing research capacity

Career development of clinical doctorates with translational and patient-oriented research interest

Career development of independent clinical scientists during their development

Career development for clinical researchers translating basic discoveries into clinical treatments

Research grant for clinical researchers translating basic discoveries into clinical treatments

Multi-project research involving a number of independent investigators

Center core grants to support shared resources, common goals

Large, mechanism-driven research projects

Small research grant program

Support for conferences and scientific meetings

Small research projects in biomedical/behavioral sciences conducted by students/faculty in health professional or other academic school that have not been major recipients of NIH research grant funds (aka Academic Research Enhancement Award or AREA)

Research project that is exploratory

Resource-related research projects that will enhance the capability of resources to serve biomedical research (can be used to enhance research infrastructure)

Education projects that promote appreciation for and interest in biomedical research, provide additional training in specific areas, develop ways to disseminate scientific discovery into public health and community applications

Clinical trial planning grant

Biomedical research shared instrumentation grant program that makes available research instruments which will be used on a shared basis - available to institutions with a high concentration of NIH extramural research awards

Pre-doctoral and post-doctoral training program

Program to enable minority institutions to make National Research Service Awards to individuals selected by them for undergraduate research training in the biomedical and behavioral sciences (aka Minority Access to Research Careers or MARC)

Program to increase the number of well-trained minority scientists in biomedical disciplines and to strengthen the research and teaching capabilities of minority institutions through a variety of training mechanisms such as visits by experienced scientists to minority institutions or workshops/conferences designed to enhance the research training experience of students/faculty from minority institutions (aka MARC Ancillary Training Activities)

Program to support comprehensive interdisciplinary research training programs at the undergraduate, predoctoral and/or postdoctoral levels, by capitalizing on the infrastructure of existing multidisciplinary and interdisciplinary research programs (aka Interdisciplinary Research Training Award)

01 Cooperative Agreement Research Projects used when substantial involvement is anticipated between the awarding institute and the awardee

Cooperative Agreement Conferences used to support international, national or regional meetings, conferences and workshops where substantial programmatic involvement is planned

Current as of March 2011 as per the website (http://grants.nih.gov/grants/funding/funding_program.htm)

conditions have been met; and (iii) adherence to specific, pre-determined timelines. Foundations sometimes put limitations on number of applicants per institution, so be sure to notify the Office of Research Services at your institution of your interest in submitting a funding request to a foundation. Again, let the Corporate and Foundations Office in your Office of Research Services work on your behalf in seeking out the best-fit foundation for your project.

\section{ENDOWMENT OR ACADEMIC DEVELOP- MENT FUNDING SOURCES}

Many tiers are present within academic institutions. At the university level, there are seed grants, center development funds and others. At the college level, there may be professional and faculty development funds. At the department level, there may be alumni donations and departmental gifts. At each level, there may be funds that allow allocations for outcomes studies, active learning trials, pilot research for preliminary data collection and other venues for research.

\section{FREQUENCY OF GRANT SUBMISSIONS}

If you ask a seasoned researcher with a strong track record of research funding how often he/she submits grants, you will receive variations on the same answer, which is to apply continuously, tirelessly, vigorously, 


\section{FOCUS: BUILDING RESEARCH THROUGH MLS CURRICULA}

Table 4. Examples of Agency, Association, Organization and Society Funding Sources

$\begin{array}{ll}\text { Agency for Healthcare Research and } & \text { www.ahrq.gov } \\ \text { Quality } & \\ \text { American Cancer Society } & \text { www.cancer.org } \\ \text { American Chemical Society } & \text { www.acs.org } \\ \text { American Diabetes Association } & \text { www.diabetes.org } \\ \text { American Heart Association } & \text { www.americanheart.org } \\ \text { American Lung Association } & \text { www.lungusa.org } \\ \text { American Society for Clinical } & \text { www.ascls.org } \\ \text { Laboratory Science } & \\ \text { American Society for Clinical Pathology } & \text { www.ascp.org } \\ \text { American Stroke Association } & \text { www.strokeassociation.org } \\ \text { World Health Organization } & \text { www.who.int }\end{array}$

diligently, determinedly and unceasingly. However, be aware there is no double dipping allowed which means that while a project may be sent to several funding agencies, only one grant per project can be accepted if the grant receives multiple awards. If you ask this same seasoned researcher if he/she has ever received a rejection letter, you will receive the same answer which is "of course". What is of grave importance for continuation of a successful research program is the way you deal with the non-award letter. Seasoned researchers will tell you to not take the non-award notice personally: take it constructively and view it as a no-cost, high-quality, critical review of your science. Learn from the reviewer's suggestions, criticisms and concerns. Use the criticism to make your science better. Sometimes reviewers offer help, such as verbal guidance with specific experiments or references of which they think will strengthen your scientific arguments. Integrate an address of the reviewers' concerns into your subsequent grant submission.

Inherent with the grant submission process is the fact that real and unreal expectations exist. Real expectations of the grant writer are: the ability to assemble necessary preliminary data and appropriate individuals (e.g., collaborators, research subjects, technical and administrative support) to perform the project; the ability to write a document that is highly focused, innovative and relevant; and the ability to execute the grant in the event of a funding award outcome. How long it takes to put together a proposal depends upon the individual: how much time per day is dedicated to writing and grant-related issues; how much assistance the grant writer has; and what type of grant is being submitted thereby indicating how long and involved the grant request needs to be.

\section{RESEARCH REWARDS AND OUTCOMES}

While there are many challenges to research, numerous rewards are also present. Immediate tangible rewards include grant funding for the project, publications and presentations (paper, seminar, poster formats) for students and faculty. Immediate intangible rewards include the elation of making a scientific discovery and realizing its medical importance as well as the satisfaction of observing a student blossom because of the research experience. Long-term results are that this encounter with active learning by students and faculty has the potential to develop an enduring sense of inquiry, an avenue for life-long learning, a commitment to the profession and an ability to apply scientific knowledge to everyday life and real-world problems. Indeed, a review of the literature indicates that undergraduate students' participation in hands-on research encourages students to pursue advanced degrees and careers in fields such as science, technology, engineering and mathematics. ${ }^{2}$ Students who participate in research because they are truly interested and who become involved in the culture of research (attending conferences, authoring journal papers, presenting their research results) are the most likely to experience positive outcomes such as increased interest in life-long learning and professional commitment. ${ }^{2}$ Results of many studies indicate that the inculcation of enthusiasm is the key element in the outcome of a positive research experience and the earlier the research exposure, the better. $^{2}$

Students enrolled in undergraduate science-related disciplines today are the source of tomorrow's scientists. It is important to identify and capture their scientific interest and curiosity and make the thrill of scientific discovery a reality to them. The National Survey of Student Engagement 2007 Annual Report ${ }^{6}$ and the Association of American Colleges and Universities ${ }^{7}$ have identified the most promising high impact practices that enhance student engagement and increase student success. These include first-year seminars, common intellectual experiences, learning communities, service learning, undergraduate research, study abroad and other experiences with diversity, internships, and capstone courses and projects. Therefore, the recommendation for educators is to make it possible for every student to participate in at least two high impact 


\title{
FOCUS: RESEARCH IN CLINICAL LABORATORY SCIENCE
}

activities during their undergraduate program with one in the first year and one later related to their major field. ${ }^{6}$ Following this recommendation in the MLS curriculum with research as a high impact practice is a means to better serving our students and our profession.

\section{REFERENCES}

1. American Society for Clinical Laboratory Science Position Paper. Advanced practice: Doctorate in clinical laboratory science 2005. Available at http://www.ascls.org. Approved Status: July 2005.

2. Russell SH, Hancock MP, McCullough J. Benefits of undergraduate research experiences. Science 2007;316:548-9.

3. Alberts B. Redefining science education. Science 2009;
323:437.

4. Mundt L, Shanahan K. ASCLS members perceptions regarding research. Clin Lab Sci 2009;22(3):170-5.

5. Rohde RE, Falleur DM, Redwine GD, Patterson TL. Growing our own: teaching and doing research in CLS. Clin Lab Sci 2010;23(3):3-11-8.

6. National Survey of Student Engagement (Annual Report 2007). Experiences that matter: enhancing student learning and success. http://nsse.iub.edu/NSSE_2007_Annual_Report.

7. The Association of American Colleges and Universities. A Guide to Effective Educational Practices, Appendix to the document entitled College Learning for the New Global Century, 2007. http://www.aacu.org/leap/documents/GlobalCentury_ final.pdf

\section{Purchase the recorded versions of the 2011 ASCLS Annual Meeting}

\section{Earn P.A.C.E. credit by January 31, 2012 !}

Puchase and watch the recorded education presentations from the 2011 ASCLS Annual Meeting by January 31, 2012 and earn P.A.C.E. ${ }^{\circledR}$ credit

Experience scientific sessions presented as synchronized slides and audio.

\author{
Download MP3 files - $\$ 149$ \\ CD-ROM - \$169 plus shipping \\ Purchase Individual Sessions \\ Download MP3 file - $\$ 20 /$ session
}

Purchase the Complete Conference Package

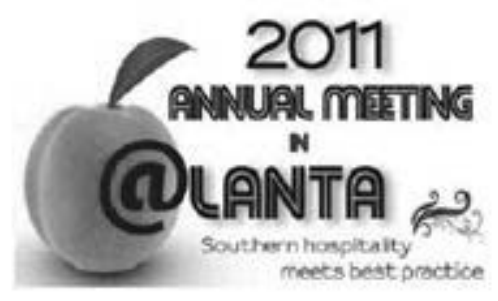

For more information, go to http://www.ascls.org/?ASCLSemeeting 